\title{
ADAM - A VIRTUAL HUMANOID ROBOT MODEL BASED ON OPEN SOURCE APPROACH
}

\author{
Matheus França ${ }^{a}$, Fredson Oliveira ${ }^{b}$, Tiago Souza ${ }^{a}$, Oberdan Pinheiro ${ }^{a}$ \\ a Senai Cimatec, Brasil. \\ b Área 1, Brasil.
}

\begin{abstract}
The Robotics has been driven by the possibilities of using robots to assist human beings. The design of a humanoid robotic system aims to obtain a machine adapted to the human environment and that can perform tasks to assist people with greater adaptability and ease of execution. This article presents the humanoid robot Adam, who will have an open architecture platform for simulations. The prototype will be used as a testing ground and thus promote the advances in the most diverse techniques in robotics and artificial intelligence. Adam is a virtual humanoid robot, and this article is about it and its virtual environment.
\end{abstract}

Keywords: Humanoid; 3D printing; Robotics.

\section{ADAM - UM MODELO DE ROBÔ VIRTUAL HUMANOIDE BASEADO EM ABORDAGEM DE CÓDIGO ABERTO}

Resumo: A robótica tem sido impulsionada pelas possibilidades da utilização de robôs para auxiliar o ser humano. O projeto de um sistema robótico humanóide visa obter uma máquina adaptada ao ambiente humano e que possa realizar tarefas para auxiliar as pessoas com maior adaptabilidade e facilidade de execução. Este artigo apresenta o robô humanóide Adam, que terá uma plataforma de arquitetura aberta para simulações. O protótipo será utilizado como objeto de testes e assim promoverá os avanços nas mais diversas técnicas de robótica e inteligência artificial. Adam é um robô humanóide virtual, e este artigo trata do seu ambiente virtual.

Palavras-chave: Humanoide; Impressão 3D; Robótica. 


\section{INTRODUCTION}

The interest and possibilities involved in humanoid robots, stimulate a substantial increase in their development. Currently there are several humanoid structures that can be categorized as: humanoids with wheels, humanoids with legs and similar to humans $[1,2,3]$. This research project proposes a simulated legged humanoid prototype with open source approach. The project was initially planned to be an experimental platform for study of the role of morphology in sensorimotor control, in human-robot interaction and in cognitive development.

The Adam robot can be a useful virtual platform for humanoid robotics, on which various technologies can be developed.

\section{METHODOLOGY}

The Adam simulator was designed to reproduce as accurately as possible the physics and dynamics of a real robot and its environment. The simulated robot is composed of several rigid bodies (links) connected by articulated structures (joints). It was built by collecting data directly from the design specifications of the physical robot (already in building process), to obtain an exact replica (for example, height, mass, degrees of freedom) of the Adam prototype. Environmental parameters such as gravity, mass of objects, friction and joints are based on real world conditions and interaction between physical Adam and real environments.

The design and simulations of structural efforts were developed with the software Fusion 360 [4] . The initial phase of simulation of Adam robot was based on the following components: 24 LB-16A servo motors from LOBOT and 6 rds5160 from DSSERVO, 13 gyroscopes mpu6050, 10 sparkfun force sensitive resistor with 0.5" each, 1 Intel Realsense d435. These components are chosen based on the idea that the project must be cheaper and get a high degree of freedom, being available for the most people.

\subsection{Open-source approach}

The humanoid simulation presented here was created using open source libraries to allow free distribution to any researcher, without requiring the purchase of proprietary or restricted and expensive licenses.

The development framework, the simulation environment and the 3D visualization tool used were ROS (Robot Operating System), Gazebo and Rviz, respectively.

\subsection{Structure Sizing}

The study of the mechanics of the human biological system will result in a better understanding of the movements and forces involved in the system. The analysis of proportions, rigidity, flexibility and joints allowed us to understand the geometries, dimensions and efforts in the human body [5].

The robot Adam was planned to be 1 meter tall and weigh $6 \mathrm{~kg}$ (after physically built) and keep anthropomorphic characteristics.

Dimensions presented in Figure 1 were taken from studies of the human body and illustrates the sizing calculations discussed below [6]. 
Figure 1. a) Survey of human anthropomorphic proportions [7], b) Adam's front view in software Fusion 360.
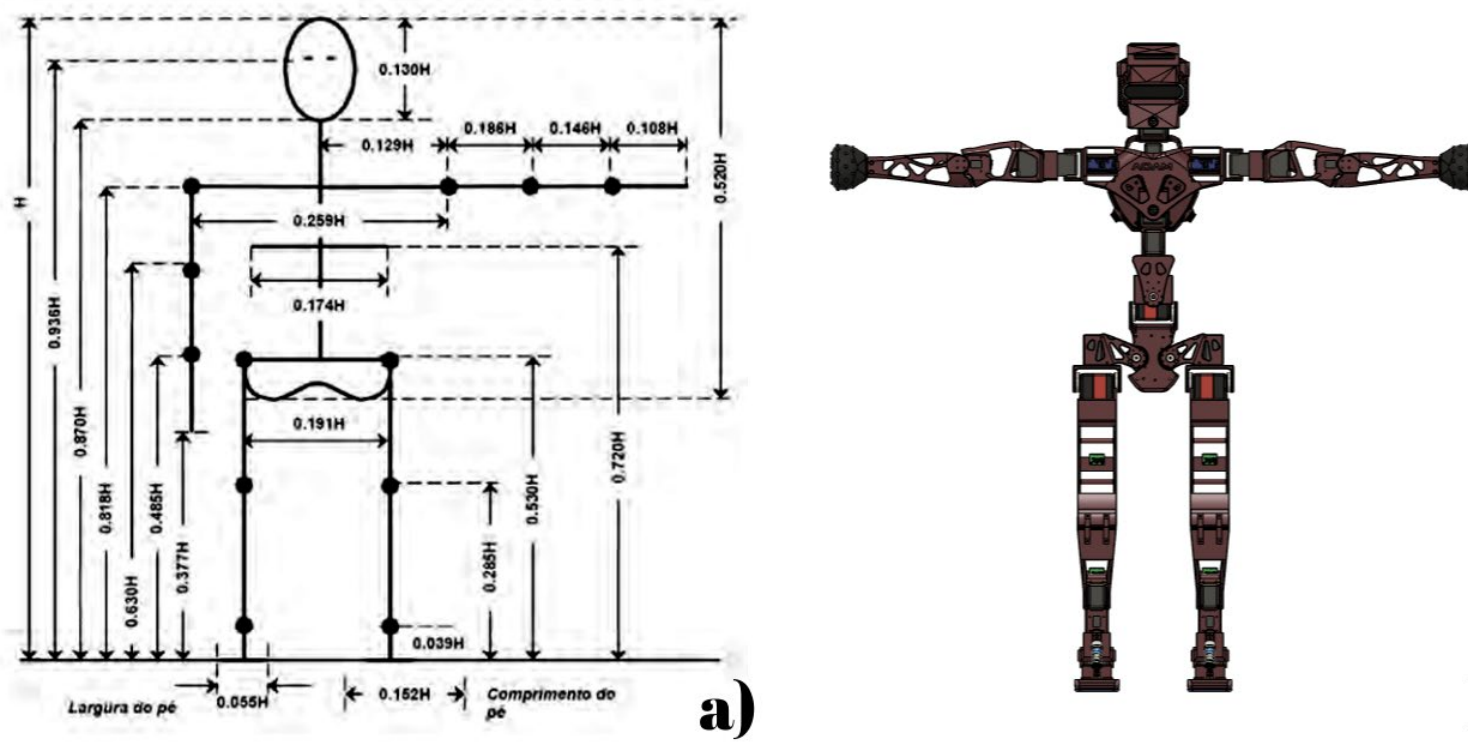

The equations 1 and 2 were used for each joint in the sketch created for the robot and illustrates the total expected dimension in comparison to the human body, i.e. it demonstrates for a given member, what the total body size would be. Based on these numbers it is possible to estimate the final height of the prototype.

Foot height (FH):

$$
\begin{gathered}
F H=0.043 m \\
F H=0,039 * H \Rightarrow H \cong 1.10256 m
\end{gathered}
$$

\section{Where:}

$\mathrm{H}=$ total height of the robot Adam.

$0.039=$ constant extracted from figure 1 for the member shown in the calculation .

$\mathrm{FH}=$ Foot height (distance between the ground and robot's ankle, see figure 1)

Finally Adam's weight and inertial parameters are estimated by loading the model parts and materials into the Fusion 360. A final weight of approximately $6 \mathrm{~kg}$ and the inertias for each part are calculated and added to the urdf file. The robot has a total of 32 DoF (degrees of freedom); Two of these 32 joints are purely passive [8], as shown in table 1.

Table 1. Degrees of freedom (DoF).

\begin{tabular}{|c|c|}
\hline Articulation & DoF number \\
\hline Foot / Ankle & $3(\mathrm{x} 2)$ \\
\hline Toe (Passive joints) & $1(\mathrm{x} 2)$ \\
\hline Knee & $1(\mathrm{x} 2)$ \\
\hline Hip & $3(\mathrm{x} 2)$ \\
\hline Body & 5 \\
\hline Arm & $4(\mathrm{x} 2)$ \\
\hline Head & 3 \\
\hline Total & 32 \\
\hline
\end{tabular}




\subsection{Computer Aided Design (CAD) and Structural Analysis}

The $3 \mathrm{~d}$ design of the robot, as shown in figure 2 is needed for the virtual model of the robot (URDF, with some parameters mentioned in section 2.2.) and will be useful for building the physical structures. Made in Fusion 360 software, the model was also used for testing freedom of movement, strength, deformation and correction of errors.

Figure 2. Adam's Fusion view.

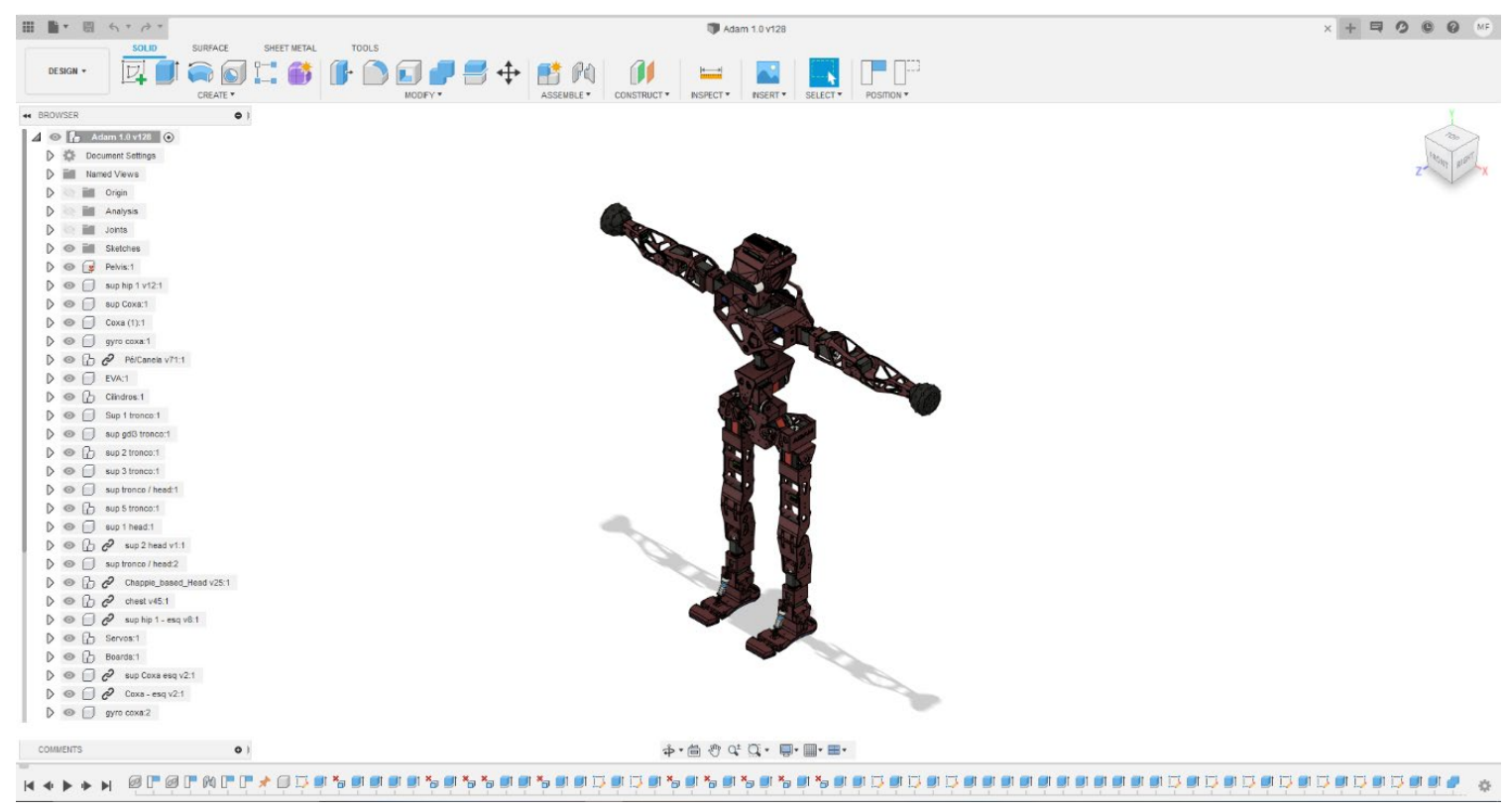

To correctly choose the servo motors, it was necessary to calculate the forces that are attached to each axis of the actuators, so that they support the dynamics of the structure. In order to know these forces that are acting on the axis, it was necessary to analyze the structure when the three-dimensional model is nearly complete, thus calculating the moment on each of the joints. For this, we use the principles of classical mechanics [9], applying the torque definition $(\mathrm{C}=\mathrm{r} \times \mathrm{F})$. Tables 2, 3 and 4 represent the maximum loads for each joint:

Table 2. Right and left legs.

\begin{tabular}{|c|c|}
\hline Servo right / left leg & Torque Max. (N.m) \\
\hline Thigh Sagittal Axis & 1,924 \\
\hline Thigh Cross Axis & 2,875 \\
\hline Thigh Longitudinal axis & 1,948 \\
\hline Knee & 0,818 \\
\hline Heel Longitudinal axis & 0,376 \\
\hline Heel Sagittal Axis & 0,216 \\
\hline Heel Cross Axis & 0,082 \\
\hline
\end{tabular}

Table 3. Right and left arms.

\begin{tabular}{|c|c|}
\hline Servo right / left arm & Torque Max. (N.m) \\
\hline Elbow & 0,267 \\
\hline Shoulder Longitudinal Axis & 0,459 \\
\hline Shoulder Cross Axis & 0,726 \\
\hline Shoulder Sagittal Axis & 0,844 \\
\hline
\end{tabular}

Table 4. Body. 


\begin{tabular}{|c|c|}
\hline Servo Body & Torque Max. (N.m) \\
\hline Lumbar Sagittal Axis & 4,928 \\
\hline Lumbar Cross Axis & 3,445 \\
\hline Chest Longitudinal Axis & 2,963 \\
\hline Chest Sagittal Axis & 1,417 \\
\hline Chest Cross Axis & 1,314 \\
\hline Neck Longitudinal Axis & 0,569 \\
\hline Neck Sagittal Axis & 0,455 \\
\hline Neck Cross Axis & 0,341 \\
\hline
\end{tabular}

After the drawing was done, it was necessary to validate the parts through the simulations. During the model analysis, three-dimensional stresses and strains are developed in several directions on each part of the robot. A usual way of expressing these multidirectional tensions is to summarize them to an equivalent tension, also called Von-Mises stress [10], as shown in figure 3.

Figure 3. Von-Mises (A: real, B: projection).
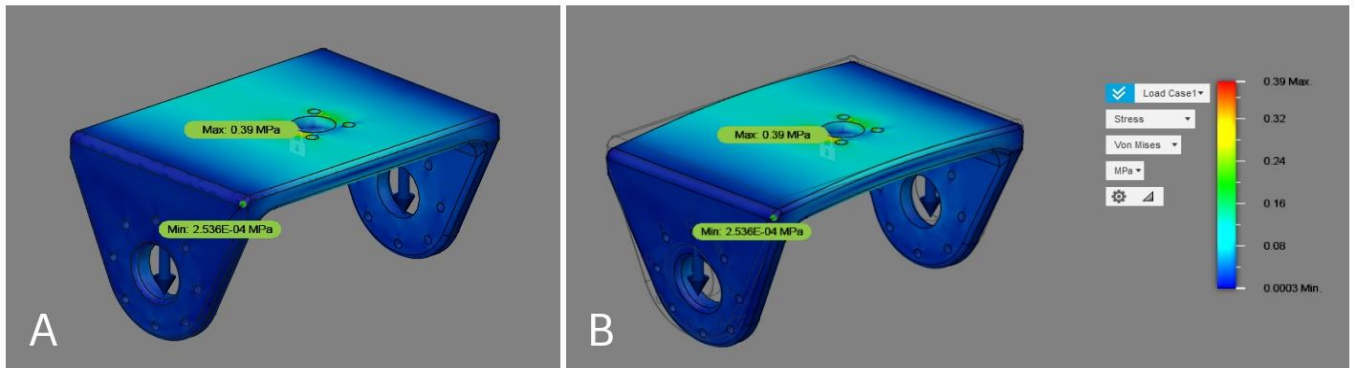

For the displacement test (figure 4) and reaction force (figure 5) the results show the deformed shape (with a projection scale) of the model after the solution.

Figure 4. Displacement (A: real, B: projection).
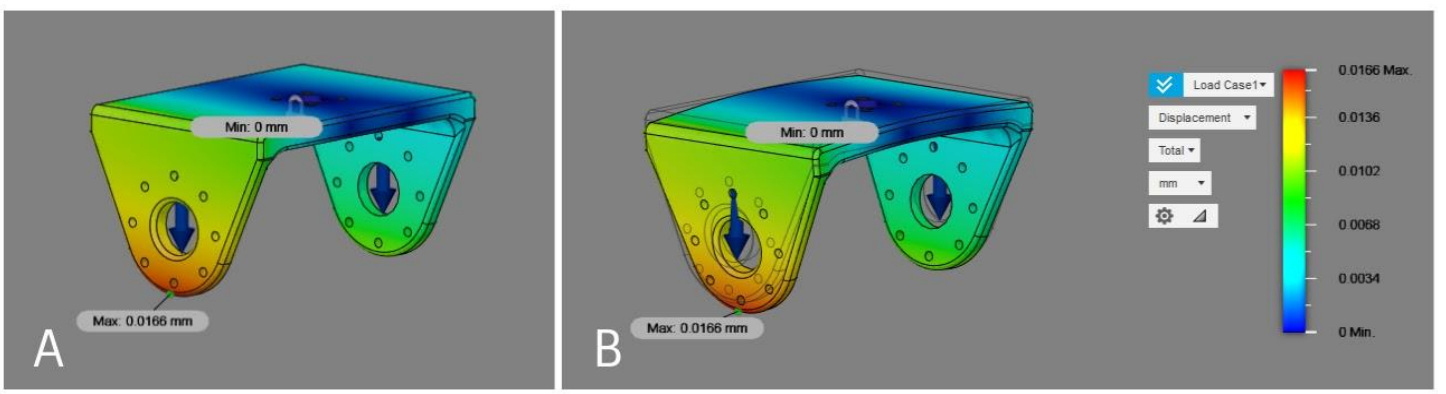

Figure 5. Reaction force (A: real, B: projection).
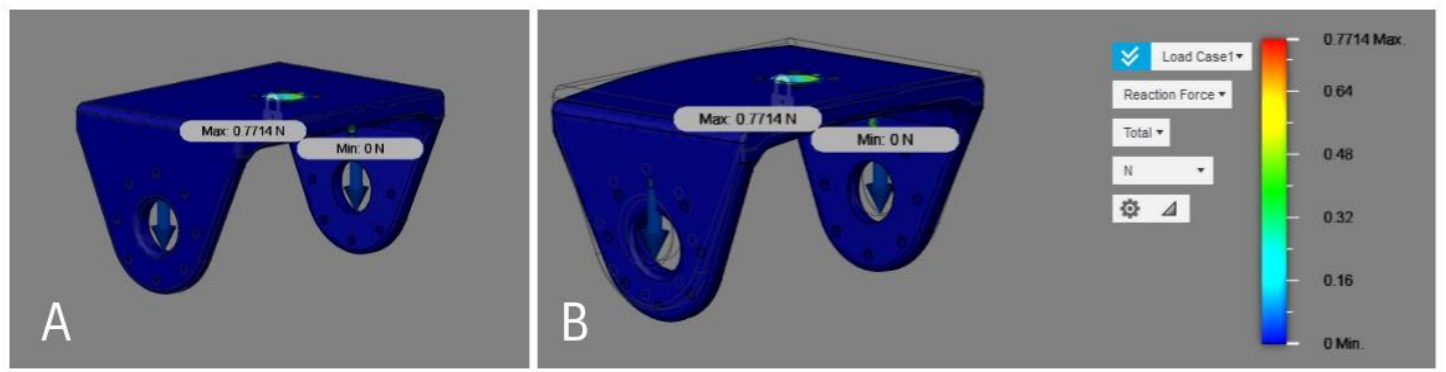

\subsection{Simulated model}


After creating the robot in the chosen cad software and structural analysis, it was necessary to generate the URDF (Unified Robot Description Format), which will be the description of the robot to be read by softwares as gazebo and moveit (figure $6)$.

Figure 6. a) Adam in Rviz with camera and Movelt plug-in b) Adam in the Gazebo simulator.

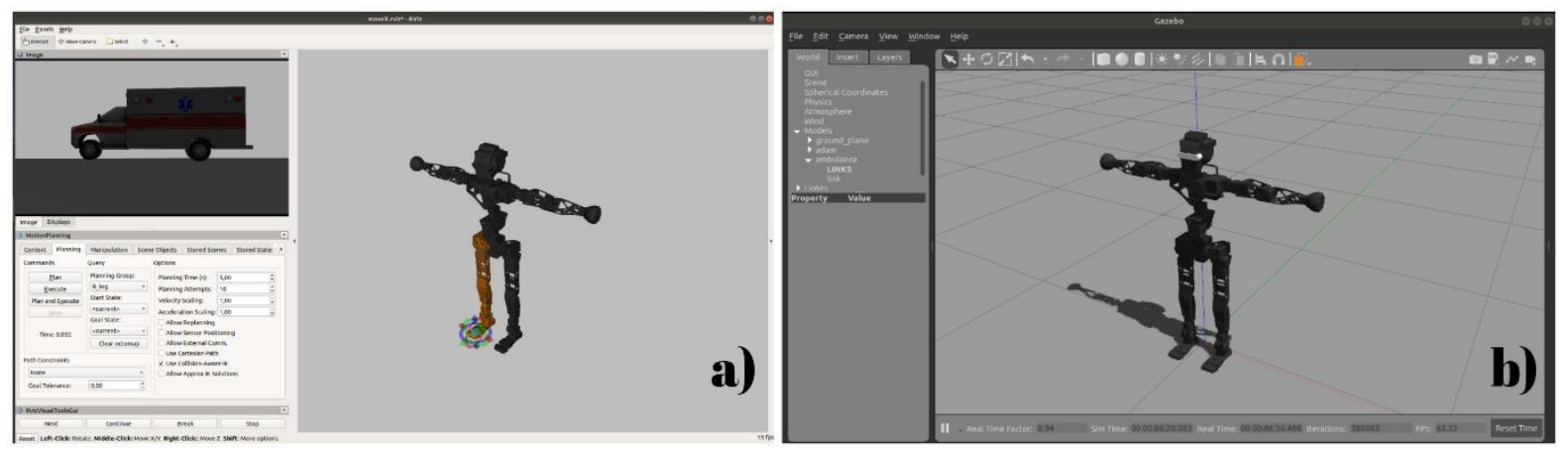

The robot model consists of several rigid bodies (links) connected through a number of different joints. All sensors of the physical robot were implemented in the simulation, such as force sensors, gyroscopes and cameras.

\subsection{ROS-based file and controller system}

Packages are the main units for organizing software in ROS [11]. A package can contain nodes (figure 7), configuration files or anything else that is useful to be organized together. The files that describe Adam and its controllers are organized following the ROS packages organization system.

Figure 7. Representation of part of Adam's node network in ROS.

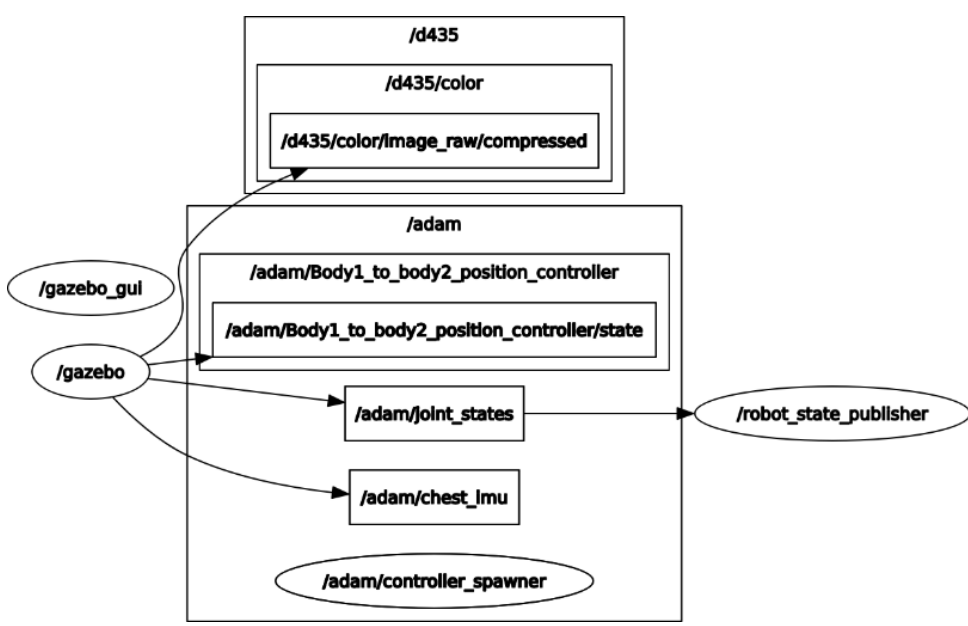

Adam uses these simulated ROS PID controllers [12] (internal parameters) to drive the joints. To fine-tune the PID gains we use the ROS rqt with the dynamic reconfigure tool and save these values in the robot settings.

\subsection{Movelt and IKFast}

Movelt [13] contains motion planning plug-ins (currently using OMPL), collision detection (currently using Fast Collision Library (FCL)), kinematics plug-in (currently using OROCOS Kinematics and Dynamics Library (KDL) for kinematics forward and reverse as custom plugins).

The humanoid Adam uses these features to generate the robot's collision matrix and kinematics, as well as motion planning. 
IKFast [14] is a powerful inverse kinematics solver and can be used to replace the standard KDL, to generate faster solutions. It is provided by the OpenRAVE motion planning software.

The standard option KDL and the IKFast were tested and the results obtained with Adam for the move group, which constitute the two legs (taken as an example), got to have a performance of $60 \%$ faster in the execution with IKFast.

\section{RESULTS, CONCLUSION AND FUTURE PERSPECTIVES}

The robot controllers were implemented and their parameters were set. The moveit and Ikfast interface was also integrated as shown in figure 9.

Figure 9. Leg movement simulation in: a) rviz environment, b) gazebo environment.
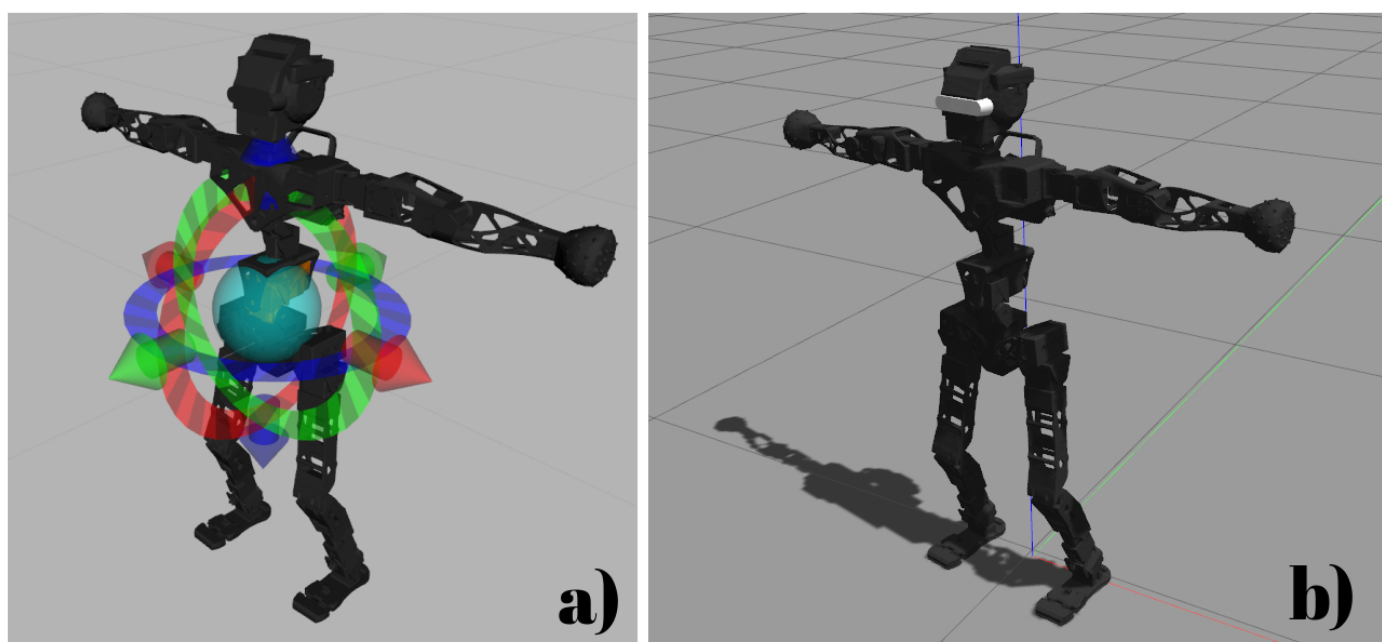

The vision plug-in for the Intel Realsense sensor was implemented and can be seen in the figure 10.

Figure 10. a) Environment in gazebo, b) Rviz visualization with point cloud.
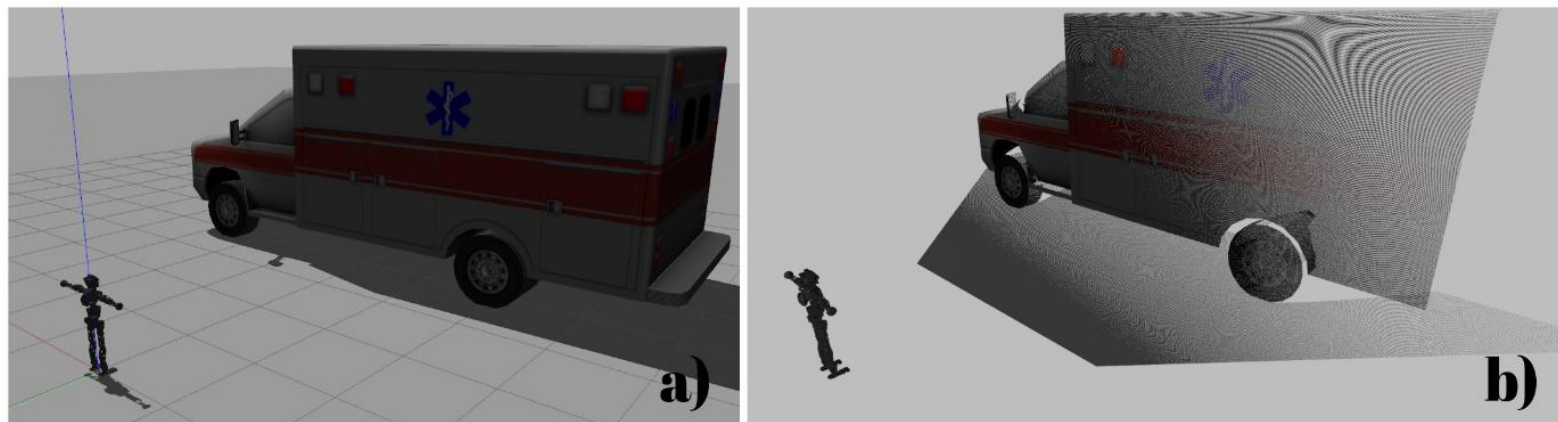

The Adam simulator will be used in the future for experiments in the development of new techniques for walking stability and environment mapping.

In simulated modeling, it is suggested to add features in the environment, this will allow the scenario to be more dynamic, in order to allow different types of experiments. Finally, use systematic tests and the replication of simulation studies with the physical robot.

A physical Adam robot will be built for future tests and comparisons with the simulated version. 
All the sensors (camera, IMU and force sensitive resistors) and actuators (servos) were responsive in the virtual environment as expected. The depth sensor goes well to generate good point clouds.

After verification and some more in-depth tests on the vision and walking planning codes, the complete code will be made available to other researchers, promoting the area of robotics and artificial intelligence.

\section{REFERENCES}

${ }^{1}$ POLVERINI, Matteo Parigi et al. Multi-Contact Heavy Object Pushing With a Centaur-Type Humanoid Robot: Planning and Control for a Real Demonstrator. IEEE Robotics and Automation Letters, v. 5, n. 2, p. 859-866, 2020.

${ }^{2} \mathrm{ZHOU}$, Haitao et al. Model Decoupling and Control of the Wheeled Humanoid Robot Moving in Sagittal Plane. In: 2019 IEEE-RAS 19th International Conference on Humanoid Robots (Humanoids). IEEE, 2019. p. 1-6.

${ }^{3}$ RADFORD, Nicolaus A. et al. Valkyrie: Nasa's first bipedal humanoid robot. Journal of Field Robotics, v. 32, n. 3, p. 397-419, 2015.

${ }^{4}$ Mesquita, Brehme \& Junior, Armano \& Silva, Emilly \& Junior, Ermilton \& de Souza Almeida, Marcus. APLICAÇÃO DE CAD, CAM E IMPRESSÃO 3D NA CONSTRUÇÃO ESTRUTURAL DE ROBÔ, 2019.

${ }^{5}$ FAISAL, Abu llius et al. Monitoring methods of human body joints: State-of-the-art and research challenges. Sensors, v. 19, n. 11, p. 2629, 2019.

${ }^{6}$ SABINO, Rémi. Estrutura híbrida de locomoção para um robô humanóide. 2009. Tese de Doutorado. Dissertação de Mestrado, Mestrado Integrado em Engenharia Mecânica, Universidade de Aveiro.

${ }^{7}$ VISSER, Ewart J. Assessment of Human-Likeness and Anthropomorphism of Robots: A Literature Review. In: Advances in Neuroergonomics and Cognitive Engineering: Proceedings of the AHFE 2020 Virtual Conferences on Neuroergonomics and Cognitive Engineering, and Industrial Cognitive Ergonomics and Engineering Psychology, July 16-20, 2020, USA. Springer Nature, 2020. p. 190.

${ }^{8}$ YUAN, Kai; CHATZY NIKOLAIDIS, Iordanis; LI, Zhibin. Bayesian optimization for whole-body control of high-degree-of-freedom robots through reduction of dimensionality. IEEE Robotics and Automation Letters, v. 4, n. 3, p. 2268-2275, 2019.

${ }^{9}$ COSTA, Gilberto de Oliveira. Identificação de parâmetros cinemáticos e controle dinâmico de robôs móveis com rodas tipo skid-steering utilizando múltiplos sensores inerciais. 2019.

${ }^{10}$ WANG, Hongxin et al. The robust fail-safe topological designs based on the von Mises stress. Finite Elements in Analysis and Design, v. 171, p. 103376, 2020.

${ }^{11}$ QUIGLEY, Morgan et al. ROS: an open-source Robot Operating System. In: ICRA workshop on open source software. 2009. p. 5.

12 PERNG, Jau-Woei; HSIEH, Shan-Chang. Design of digital PID control systems based on sensitivity analysis and genetic algorithms. International Journal of Control, Automation and Systems, v. 17, n. 7, p. 1838-1846, 2019.

${ }^{13}$ David Coleman, Ioan A. Șucan, Sachin Chitta, Nikolaus Correll, Reducing the Barrier to Entry of Complex Robotic Software: a Movelt! Case Study, Journal of Software Engineering for Robotics, 5(1):316, May 2014. doi: 10.6092/JOSER_2014_05_01_p3.

14 D. Coleman, Integrating IKFast with Movelt!: A Tutorial. http://docs.ros.org/hydro/api/moveit_ikfast/html/doc/ikfast_tutorial.html (2014). 